\title{
Benefícios do ácido kójico no tratamento de hipercromias
}

\author{
Benefits of kojic acid in the treatment of hyperchromis \\ Beneficios del ácido kójico en el tratamiento de la hipercromia
}

Recebido: 24/11/2021 | Revisado: 01/12/2021 | Aceito: 02/12/2021 | Publicado: 12/12/2021

\author{
Cintia da Silva Oliveira \\ ORCID: https://orcid.org/0000-0002-5039-3688 \\ Faculdade Independente do Nordeste, Brasil \\ E-mail:cintiasilva2k17@gmail.com \\ Giovanna Inácio de Andrade \\ ORCID: https://orcid.org/0000-0002-7831-2755 \\ Faculdade Independente do Nordeste, Brasil \\ E-mail:geuandrade_17@outlook.com \\ Jeane Rocha Santos \\ ORCID: https://orcid.org/0000-0002-1398-3638 \\ Faculdade Independente do Nordeste, Brasil \\ E-mail: Jeane@fainor.com.br
}

\begin{abstract}
Resumo
As hipercromias de pele são sequelas corriqueiras mediante alguma desordem no processo fisiológico, dentre elas, envelhecimento, alterações hormonais, inflamações, alergias e exposição solar excessiva. O processo de hiperpigmentação tecidual ocorre devido a maior produção de melanina pela célula nomeada melanócito, anormalidade tecidual que afeta inúmeras pessoas e consequentemente a qualidade de vida das mesmas. Tem como objetivo descrever através de literaturas já existentes os benefícios do ácido kójico no tratamento das hipercromias de pele. Este estudo trata-se de uma revisão integrativa da literatura, teve como fonte de dados artigos científicos e livros já existentes em plataformas online. Foram encontradas pesquisas experimentais e não experimentais que comprovam a eficácia do ativo de ácido kójico em sua concentração pura ou em combinação com outras substâncias clareadoras. Embora existam poucos estudos a cerca da temática, conclui-se que o ativo despigmentante de ácido kójico é uma alternativa segura e eficiente no tratamento de manchas, devido sua formulação natural e não citotóxica.
\end{abstract}

Palavras-chave: Ácido Kójico; Hiperpigmentação; Despigmentante.

\begin{abstract}
Skin hyperchromias are common sequelae due to some disorder in the physiological process, including aging, hormonal changes, inflammation, allergies and excessive sun exposure. The tissue hyperpigmentation process occurs due to increased production of melanin by cells named melanocyte, tissue abnormality that affects many people and consequently their quality of life. Its objective is to describe through existing literature the benefits of kojic acid in the treatment of cutaneous hyperchromia. This study is an integrative literature review, using scientific articles and books that already exist on online platforms as a data source. Experimental and non-experimental researches were found that prove the effectiveness of the active kojic acid in its pure concentration or in combination with other lightening substances. Although there are few studies on the subject, it is concluded that the depigmenting active of kojic acid is a safe and efficient alternative in the treatment of spots, due to its natural and non-cytotoxic formulation.
\end{abstract}

Keywords: Kojic Acid; Hyperpigmentation; Depigmenting.

\section{Resumen}

Las hipercromías cutáneas son secuelas habituales debidas a algún trastorno en el proceso fisiológico, como el envejecimiento, los cambios hormonales, la inflamación, las alergias y la exposición excesiva al sol. El proceso de hiperpigmentación tisular se produce debido al aumento de la producción de melanina por parte del melanocito denominado, una anomalía tisular que afecta a muchas personas y su calidad de vida. Su objetivo es describir a través de la literatura existente los beneficios del ácido kójico en el tratamiento de la hipercromía cutánea. Este estudio es una revisión integradora de la literatura, utilizando artículos científicos y libros que ya existen en plataformas en línea como fuente de datos. Se encontró que investigaciones experimentales y no experimentales demostraron la efectividad del ácido kójico activo en su concentración pura o en combinación con otras sustancias aclarantes. Aunque existen pocos estudios sobre el tema, se concluye que el despigmentante activo del ácido kójico es una alternativa segura y eficaz en el tratamiento de las manchas, debido a su formulación natural y no citotóxica. Palabras clave: Ácido kójico; Hiperpigmentación; Despigmentante. 


\section{Introdução}

A cor da pele é determinada principalmente pela presença da melanina, um pigmento denso de alto peso molecular que possui coloração castanho claro, mas quando concentrado assume um aspecto enegrecido (Lin, 2007). As desordens na coloração da pele originam-se em um aumento na quantidade da melanina que é produzida. As principais causas para este aumento são: o processo de envelhecimento, alterações hormonais, inflamações, alergias e exposição solar, dentre outros (Gonchoroski \& Corrêa, 2005).

Callender et al. (2011) referem que as hiperpigmentações são resultantes da maior produção de melanina, podendo surgir na epiderme ou na derme pela ação dos melanócitos (células especializadas em produzir melanina). Desta forma, as agressões ao tecido podem resultar em um aumento da produção de melanina. Segundo Gonchoroski e Corrêa (2005), as hipercromias são desordens na pigmentação da pele, tornando-a mais escura do que a sua coloração normal e podem provocar um aspecto estético indesejado. As principais hipercromias são: melasma (cloasma), efélides (sardas), lentigos, hipercromias pós-inflamatórias e hiperpigmentação periorbital (Baumann, 2004).

Dentre as opções de tratamento os ativos despigmentantes apresentam resultados relevantes, os mesmos possuem finalidade de proporcionar o clareamento das hipercromias cutânea. O mecanismo de ação dos ativos despigmentantes se dá pela diminuição na produção de melanina, interferindo na principal enzima responsável pela sua síntese: a tirosinase (Moura et al., 2017).

Borges (2010) descreve que, o tratamento de hipercromias está diretamente ligado com a extensão do tecido lesado. O tratamento por meio de substâncias clareadoras deve conter o pH inferior ao da pele, com a finalidade de tornar o tecido mais ácido e promover esfoliação, consequentemente uma descamação. Existem distintos meios da transferência de melanina, devido isso, é de suma importância à escolha do princípio ativo para cada finalidade de tratamento (Gonchoroski \& Corrêa, 2005).

Neste contexto, o ácido kójico mostra-se eficiente no tratamento da hipercromias, por ter ação despigmentante e não possuir caráter irritativo a pele, devido sua formulação natural, agindo no processo de formação da melanina e freando a sua produção (Silva et al., 2015). Quanto ao seu resultado, depende da frequência de aplicações, em cosméticos usados diariamente é indicada uma concentração entre 1 a 3\% (Souza et al., 2018). Sendo assim, o tratamento das hiperpigmentações pósinflamatórias consiste basicamente na utilização de substâncias de aplicação tópica (Davis et al., 2010).

Frente ao exposto, o objetivo deste estudo é descrever, através de literaturas já existentes, os benefícios do ácido kójico no tratamento das hipercromias cutânea.

\section{Metodologia}

Trata-se de uma revisão integrativa da literatura, segundo Pompeo et al (2009) a revisão integrativa permite consultar como base estudos com diferentes metodologias de pesquisa, segue criteriosamente etapas que orienta todo o processo do projeto. Mendes et. al (2008) afirma que, este tipo de estudo tem como finalidade através de literaturas já existentes gerar novos conhecimentos sobre o tema a ser tratado. A pesquisa assume caráter descritivo exploratório, de acordo Gil (2008) tem como objetivo relatar o problema de pesquisa a ser tratado e descrever os pontos importantes através do levantamento. Foram realizadas buscas em bases de dados online, com os operadores boleanos AND e OR, através dos cruzamentos de descritores: hiperpigmentação de acne OR ácido kójico, inflamação and acne, acne and ácido kójico, na fonte de dados Google acadêmico. Como critério de inclusão estudos publicado nos últimos 10 anos (2011 a 2021) e que possuíam relevância com a temática, como critério de exclusão os projetos que não apresentavam relação com o tema da pesquisa e não se enquadraram a data. Para a seleção foram selecionados 15 artigos, de início 5 descartados por não se adequarem a data, após avaliar criteriosamente foram descartados mais 4 por não apresentarem relação com a temática do estudo, por fim, filtrados foram somente 6, os quais 
se enquadraram a todos os critérios de inclusão. A análise dos dados foi apresentada através de uma tabela de fácil entendimento, dessa forma foram organizados os dados dos artigos levantados em: título, autor (es), objetivos, métodos e principais resultados. Além disso, foi realizada uma análise descritiva e comparativa com as informações obtidas através de buscas sobre o tema abordado, a fim de deixar claro a importância e os resultados do estudo. Diante disso o que mais se enquadra na pesquisa descritiva é uma análise qualitativa, pois de acordo Bauer et al. (2008) é um caminho importante para obter resultados eficientes sobre o problema abordado. O estudo seguiu todos os aspectos éticos perante a Lei de Direitos Autorais: Lei número 9.610, criada em fevereiro de 1998, assegurando que as literaturas que foram utilizadas nesse projeto serão referenciadas corretamente, de acordo a norma ABNT (associação brasileira de normas e técnicas) com isso, evitando cópias e plágios das obras consultadas.

\section{Resultados e Discussão}

Compuseram a amostra desta pesquisa 06 (seis) artigos, selecionados de acordo a relação da temática do estudo. Os resultados da pesquisa serão apresentados em um quadro de fácil compreensão (Quadro 1), contendo as informações referentes ao título, autor (es), ano de publicação, objetivos, métodos e principais resultados.

Quadro 1 - Apresentação dos artigos segundo título, autor (es), ano de publicação, objetivos, métodos e principais resultados.

Vitória da Conquista, Bahia, Brasil. 2021.

\begin{tabular}{|c|c|c|c|c|}
\hline Título & Autor \Ano & Objetivos & Métodos & Resultados \\
\hline $\begin{array}{l}\text { Desenvolvimento de } \\
\text { desodorante roll on de } \\
\text { ácido kójico como } \\
\text { alternativa para } \\
\text { clareamento de axilas. }\end{array}$ & $\begin{array}{l}\text { Luana de Menezes de } \\
\text { Souza.,et al. (2021) }\end{array}$ & $\begin{array}{lr}\text { Desenvolver } & \text { um } \\
\text { desodorante roll on a } \\
\text { base de ácido kójico, } \\
\text { como alternativa para } \\
\text { tratamento } & \text { da } \\
\text { hiperpigmentação } & \text { das } \\
\text { axilas causada por } & \text { por } \\
\text { hipercromia } & \text { pós- } \\
\text { inflamatória. } & \end{array}$ & Estudo experimental & $\begin{array}{l}\text { O Estudo concluiu que o } \\
\text { desodorante roll on desenvolvido } \\
\text { pode se configurar como uma } \\
\text { alternativa para tratamento da } \\
\text { hiperpigmentação das axilas } \\
\text { causada por hipercromia pós- } \\
\text { inflamatória, podendo contribuir } \\
\text { assim para a diversificação de } \\
\text { desodorantes contendo AK } \\
\text { disponíveis no mercado. }\end{array}$ \\
\hline $\begin{array}{lr}\text { Efeitos do ácido kójico } \\
\text { e belides } & \text { no } \\
\text { clareamento } & \text { de } \\
\text { hipercromias da } & \text { região } \\
\text { axilar. } & \end{array}$ & $\begin{array}{l}\text { Shirley Maria } \text { de } \\
\text { Lima Solon et al. } \\
(2020)\end{array}$ & $\begin{array}{l}\text { Verificar os efeitos do } \\
\text { ácido kójico e belides no } \\
\text { tratamento de } \\
\text { clareamento das } \\
\text { hipercromias na área } \\
\text { axilar }\end{array}$ & Estudo longitudinal. & $\begin{array}{l}\text { Após sete meses de tratamento } \\
\text { notou-se uma melhora significativa } \\
\text { no clareamento das hipercromias } \\
\text { axilar de todas as voluntárias } \\
\text { envolvidas. }\end{array}$ \\
\hline $\begin{array}{l}\text { Eficácia do ácido kójico } \\
\text { em associação ao ácido } \\
\text { salicílico no tratamento } \\
\text { de hipercromias pósin } \\
\text { flamatórias em } \\
\text { diferentes fototipos de } \\
\text { pele. }\end{array}$ & $\begin{array}{l}\text { Ketelly Alves de } \\
\text { Oliveira e Rejane } \\
\text { Martins (2020) }\end{array}$ & $\begin{array}{l}\text { Comparar a efetividade } \\
\text { do ácido kójico } \\
\text { associado ao ácido } \\
\text { salicílico no tratamento } \\
\text { de hipercromias pós- } \\
\text { inflamatórias em } \\
\text { diferentes fototipos de } \\
\text { pele. }\end{array}$ & $\begin{array}{l}\text { Estudo } \\
\text { experimental. }\end{array}$ & $\begin{array}{l}\text { Foi observado que as hipercromias } \\
\text { pós-inflamatórias tiveram uma } \\
\text { redução significativa durante o } \\
\text { tratamento com ácido kójico } \\
\text { associado ao ácido salicílico. }\end{array}$ \\
\hline $\begin{array}{l}\text { Aplicações de ácido } \\
\text { kójico em preparação } \\
\text { cosmética e } \\
\text { farmacêutica. }\end{array}$ & $\begin{array}{l}\text { Majid Saeedia, } \\
\text { Masoumeh } \\
\text { Eslamifarb E } \\
\text { khadijeh Khezric. } \\
\text { (2018) }\end{array}$ & $\begin{array}{l}\text { Descrever e discutir a } \\
\text { aplicação e alta } \\
\text { capacidade do ácido } \\
\text { kójico, como um agente } \\
\text { de clareamento em } \\
\text { cosméticos e } \\
\text { preparações de cuidados } \\
\text { de saúde. }\end{array}$ & Revisão Integrativa & $\begin{array}{l}\text { Em conclusão, hoje com maciço } \\
\text { crescimento nesta indústria, a oferta } \\
\text { e demanda de ácido kójico está } \\
\text { aumentando consideravelmente. } \\
\text { Portanto, mais estudos clínicos são } \\
\text { necessários para projetar e } \\
\text { desenvolver novos produtos } \\
\text { baseados em ácido kójico. }\end{array}$ \\
\hline $\begin{array}{ll}\text { Ácido Kójico } & \text { no } \\
\text { Tratamento } & \text { do } \\
\text { Melasma. } & \end{array}$ & $\begin{array}{lr}\text { Caroline } & \text { Gomes } \\
\text { Pontes e } & \text { Dayana } \\
\text { Priscila Maia } & \text { Mejia. } \\
(2014) & \end{array}$ & $\begin{array}{l}\text { Organizar dados } \mathrm{e} \\
\text { evidências que } \\
\text { contribuem com tese da } \\
\text { eficácia do ácido kójico } \\
\text { no tratamento de } \\
\text { melasma. }\end{array}$ & $\begin{array}{l}\text { Revisão } \\
\text { bibliográfica } \\
\text { artigos e livros. }\end{array}$ & $\begin{array}{l}\text { Sua indicação é de } 1 \text { a } 3 \% \text { em } \\
\text { formulações tópicas, sendo possível } \\
\text { observar o efeito de duas a quatro } \\
\text { semanas de uso continuo, podendo } \\
\text { apresentar melhores resultados com } \\
\text { o uso de } 6 \text { meses }\end{array}$ \\
\hline
\end{tabular}




\begin{tabular}{|c|c|c|c|c|}
\hline $\begin{array}{lr}\begin{array}{l}\text { Estudo clínico } \\
\text { avaliação }\end{array} & \text { para a } \\
\text { propriedades } & \text { das } \\
\text { clareadoras } & \\
\text { associação de } & \text { ácido } \\
\text { kójico, } & \text { arbutin, } \\
\text { sepiwhite® } & \text { e } \\
\text { achromaxyl@ } & \\
\text { naabordagem } & \text { do } \\
\text { melasma, comparada à } \\
\text { hidroquinona } 2 \% \text { e } 4 \% .\end{array}$ & $\begin{array}{l}\text { Costa Adilson et al. } \\
(2011)\end{array}$ & 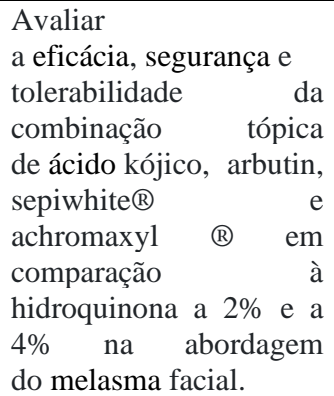 & $\begin{array}{l}\text { Estudo } \\
\text { clínico mono-cego, } \\
\text { comparativo, } \\
\text { monocêntrico }\end{array}$ & $\begin{array}{l}\text { O uso tópico } \\
\text { da associação de ácido kójico, } \\
\text { arbutin, sepiwhite® e achromaxyl } \\
\text { ® demonstrou ser eficaz } \\
\text { e seguro na abordagem } \\
\text { do melasma, apresentando-se como } \\
\text { alternativa no tratamento } \\
\text { dessa dermatose recalcitrante e } \\
\text { inestética. }\end{array}$ \\
\hline
\end{tabular}

Fonte: Dados da pesquisa.

A análise dos resultados deste estudo evidenciou efeitos satisfatórios do ácido kójico para o tratamento de hiperpigmentações indesejadas na pele, visto que melhora a textura e tonalidade do tecido cutâneo, apresentam bons resultados o ácido kójico puro ou em junção com outros ativos clareadores.

A pesquisa publicada por Solon et al. (2020) mostrou a eficácia do ácido kójico com o ativo belides no tratamento de hiperpigmentação axilar, após sete meses de uso em voluntárias, notou-se uma melhora significativa. O artigo publicado por Souza et al. (2021) conceitua o desodorante roll on de ácido kójico uma alternativa para o tratamento de hipercromias em região axilar, porém sendo necessários mais estudos para trazer novos experimentos ao uso do produto.

Ainda sobre os benefícios do ativo, Pontes e Mejia (2014) retratam a importância do ácido kójico no tratamento do melasma, o ativo é indicado de 1 a $3 \%$ em fórmulas de uso tópico, apresentando melhora entre duas a quatro semanas de uso contínuo, evidenciando resultados mais satisfatórios com o uso de aproximadamente seis meses. Costa et al. (2020) demostra a segurança e tolerância da combinação do ácido kójico, arbutin, sepwhite e achromaxyl, em comparação a hidroquinona na sua concentração 2 a 4\%, esta pesquisa teve como abordagem o tratamento do melasma através da combinação dos ativos citados. O uso do ácido kójico, arbutin, sepwhite e achromaxyl, mostrou-se seguro no tratamento do melasma em comparação ao uso da hidroquinona 2 a $4 \%$.

Uma pesquisa experimental realizada por Oliveira e Martins (2020) relatou bons resultados ao uso do ácido kójico em junção com o ácido salicílico para o tratamento de desordens pigmentares em processo pós-inflamatório em diferentes fototipos cutâneos, no resultado da pesquisa foi observado uma redução significativa das hipercromias na região tratada.

Os autores Saeedi et al. (2019) citam que o ativo de AK cresce consideravelmente na indústria farmacêutica em cosméticos como opção de tratamento para clareamento de hipercromias, devido a isso, a procura do ativo vem aumentando, os autores trazem também a necessidade de desenvolvimento de novos estudos sobre a temática e ressalta a importância de novos produtos contendo o ativo.

De acordo Kwak et al., (2010) o ácido kójico é considerado um ativo despigmentante natural, proveniente da fermentação do arroz, tem como função principal proporcionar o clareamento do tecido, seu mecanismo de ação é atuar como quelante de metais e age também nas espécies reativa de oxigênio. Entretanto, o ácido kójico traz maior eficácia em longo prazo, sendo necessário ter uma concentração mais elevada para agir na síntese da tirosina. O ácido kójico é capaz de quelar íons de cobre e bloquear a síntese da tirosinase, consequentemente melhorando as hipercromias cutâneas, destaca-se não possuir caráter não irritativo e não gerar fotossensibilidade durante seu uso (Gonchoroski \& Corrêa, 2005).

Mediante o uso do ácido kójico é possível notar melhora de duas a quatro semanas de uso, podendo ter diferença de resultado de acordo com os tipos de pele, a oleosa apresenta resposta mais lenta ao seu uso. Sobre isso, Nicoletti et al. (2011) referem que quanto maior o tempo de uso, maior será sua eficácia, apresentando resultados muito satisfatórios com aplicação contínua durante 6 meses. Em cosméticos de uso diário sua concentração deve estar entre indicado de 1 a $3 \%$.

Segundo Pontes (2014) o tratamento com o acido kójico é ideal que a pele esteja completamente limpa, para a substância permear melhor no tecido e ter a ação desejada. Devido ao seu efeito natural pode ser combinado com outros ativos 
clareadores. O AK é uma substância que não suporta temperaturas acima de $40^{\circ} \mathrm{C}$, pois quando exposto ao calor excessivo pode oxidar. Além disso, não é indicado deixar em contato com luzes (Al-Edresi \& Baie, 2010).

Dentre os inúmeros benefícios do acido Kójico, Mitani et al., (2001) trazem que o despigmentante possui ação antioxidante. Gomes et al., (2001) afirmam que o ácido kójico age na neutralização dos radicais livres sobre a pele, evitando assim efeitos nocivos. O ativo é considerado também antibactericida leve e anti-inflamatório (Rodrigues et al., 2011).

\section{Considerações Finais}

Diante do exposto conclui-se que o uso do ácido kójico é uma alternativa eficiente para o tratamento de diferentes manchas na pele, é notório os resultados satisfatórios ao uso em sua concentração pura ou em combinação com outras substâncias clareadoras. O uso contínuo do ativo de AK apresenta melhora na qualidade, textura e tonalidade do tecido hiperpigmentado.

É um dos ativos despigmentantes mais seguros do mercado devido sua formulação natural proveniente da fermentação do arroz, apresenta ação não citotóxica à pele e pode ser utilizado de forma segura e eficaz em hipercromias teciduais. Apesar da pequena quantidade de estudos experimentais sobre o tema tratado, conclui-se que o ativo de ácido kójico é eficiente no tratamento.

Ressalta-se a importância de novos estudos com abordagem no ácido kójico e seus benefícios, devido o crescimento do ativo nas indústrias farmacêuticas e sua eficiência em tratamento de hiperpigmentações teciduais. Com isso, fazem-se necessárias novas pesquisas experimentais a cerca da temática para trazer informações quanto as concentrações ideais e quanto ao tempo de tratamento ideal com o uso do ácido.

\section{Referências}

Al- Edresi, S., \& Baie, S. (2010). In-vitro and in-vivo evaluation of a photo-protective kojic dipalmitate loaded ento nano-creams. Asian Journal of Pharmaceutical Sciences. (5a ed).

Costa, A., Arruda, A. F., Pereira, L. H., Pereira, E. S., Santos, M., Calixto, F. B., \& Favaro, R. (2012). Estudo clínico para a avaliação das propriedades clareadoras da associação de ácido kójico, arbutin, sepiwhite e achromaxyl na abordagem do melasma, comparada a hidroquinona $2 \%$ e $4 \%$. Sociedade Brasileira de Dermatologia Brasil. 4(1).

Baumann, L. M. D. (2004). Dermatologia Cosmética Princípios e Práticas. Revinter. 3-4.

Borges, F. (2010). Dermato-funcional: Modalidades Terapêuticas nas Disfunções Estéticas. Phorte.

Bauer, M. W. Gaskell, G., \& Allun, N. C. (2008). Qualidade, quantidade e interesses do conhecimento: Evitando confusões. Guareschi. (7a ed.).

Callender, V.D., St Surin-Lord S., Davis, E.C \& Maclin, M. (2011). Postinflammatory hyperpig: mentation: etiologic and therapeutic considerations. Am J Clin Dermatol. 12(2):87-99.

Davis, E. C., \& Callender, V. D. (2010). Postinflammatory hyperpigmentation: a review of the epidemiology, clinical features, and treatment options in skin of color. J Clin Aesthet Dermatol. 3(7):20-31.

Gonchoroski, D. D. \& Corrêa, M. G. (2005). Tratamento da hipercromia pós-inflamatória com diferentes formulações clareadoras. Rev. Inframa. 17(3/4).

Gil, A. C. (2008). Como elaborar projetos de pesquisa. Atlas. (4a ed.) 41-42

Gomes, A. J. (2001). The antioxidant action of Polypodium leucotomos extract and kojic acid: reactions with oxygen species. Brazilian Journal of Medical and Biological Research, 34.

Kwak, S. Y., Noh, J. M., Park, S. H., Byun, J.-W., Choi, H. R., Park, K. C., \& Lee, Y. S. (2010). Enhanced cell permeability of kojic acid-phenylalanine amide with metal complex. Bioorganic \& Medicinal Chemistry Letters. 20, 738-741.

Lin Jy \& Fisher D.E. (2007). Melanocyte biology and skin pigmentation. Nature.

Moura, M. C. (2017). O uso de ácidos e ativos clareadores associados ao microagulhamento no tratamento de manchas hipercrômicas: estudo de caso.

Mendes, A. L. L., \& Fracolli, L. A. (2008). Revisão sistemática de literatura e metassíntese qualitativa: considerações sobre sua aplicação na pesquisa em enfermagem. Texto Contexto Enfermagem, 17(4), 771-779. 
Research, Society and Development, v. 10, n. 16, e263101623841, 2021

(CC BY 4.0) | ISSN 2525-3409 | DOI: http://dx.doi.org/10.33448/rsd-v10i16.23841

Mitani, H. (2001). Prevention of the photodamage in the hairless mouse dorsal skin by kojic acid as an iron chelator. European Journal of Pharmacology. 411(1), 169-174.

Nicoletti, M. A. (2002). Hipercromias: aspectos gerais e uso de Despigmentantes cutâneos. Cosmetics \& Toiletries. (14a ed.).

Oliveira, K. A., \& Vieira, R. M. (2020). Eficácia do ácido kójico em associação ao ácido salicílico no tratamento de hipercromias pós-inflamatórias em diferentes fototipos de pele. Revista eletrônica interdisciplinar, 12.

Pontes, C. G. (2012). Ácido Kójico no Tratamento do Melasma. Faculdade Cambury.

Pompeo, D. A., Rossi, L. A., \& Galvão, C. M. (2009). Revisão integrativa: etapa inicial do processo de validação de diagnóstico de enfermagem. Acta paul.enferm, 22(4),6.

Rodrigues, A. P. D., Carvalho, A. S. C., Santos, A. S., Alves, C. N., Nascimento, J. L. M., \& Silva, E. O. (2011). Kojic acid, a secondary metabolite from aspergillus. Acts as an inducer of macrophage activation. Cell Biology International. (35a ed.).

Souza, Carvalho, L., Amurim., Pereira, N., Grignoli, Cristina, L., \& Esquissato, M. (2018). O uso associado do ácido kòjico e Ácido Glicólico como alternativa à hidroquinona no Tratamento de melasma. Revista científica multidisciplinar, 2.

Saeedi, M., Eslamifar, M., \& Khezri, K. (2019). Kojic acid aplications in cosmetic and pharmaceutical preparativos. Biomed Pharmacother.

Silva, L. G., Simonis., Henrique, M., \& Mariana. (2015). Associação do peeling de ácido kójico e ácido Glicólico no tratamento de Melasma: um estudo de caso. 2237 Tcc (graduação)- curso de Estética e Cosmética, Unisc, Santa Cruz do sul.

Solon, L. M. D., Cordeiro, A. E., Viana F. C. S., \& Barbosa Martins, A. (2020). Efeitos dos ácido kójico e belides no clareamento de hipercromias da região axilar. Revista diálogos Acadêmicos, 9(1)

Souza, Menezes L., Dias Santos, G., Silva, R. A., \& Meireles Batista, C. (2021). Desenvolvimento de desodorante roll on de ácido kójico como alternativa para clareamento de axilas. Interfaces Científicas, 8(3). 